\title{
Borderline Hypertension
}

\author{
Hypertension Seminars at Östra Hospital, Göteborg, Sweden
}

\author{
Stevo Julius, Lennart Hansson, Lennart Andrén, Thorkell Gudbrandsson, \\ Ramon Sivertsson and Anders Svensson
}

\begin{abstract}
From the Department of Medicine, University of Michigan Medical Center, Ann Arbor, Michigan, USA, and the Hypertension Section, Departments of Medicine and Clinical Physiology, Östra Hospital, University of Göteborg, Göteborg, Sweden
\end{abstract}

\begin{abstract}
Borderline hypertension was the topic of one of the "Hypertension seminars" arranged by the Hypertension Section at the Östra Hospital, Göteborg, Sweden. On that occasion Professor Stevo Julius, Ann Arbor, Michigan, USA, was an invited guest. During the seminar, various aspects of borderline hypertension were discussed, e.g. the natural history, hemodynamics and management of this condition. The present review is based on these discussions.
\end{abstract}

Key words: borderline hypertension, hemodynamics, epidemiology.

Acta Med Scand 208: 481, 1980.

It has been shown beyond doubt, and there is general agreement today, that arterial pressure in any population is distributed as a continuous variable, the curves being Gaussian in shape when converted to the logarithmic scale. In other words, arterial pressure is a quantity, not a quality. With this in mind, it is not logical to treat arterial pressure as a quality and set up a dichotomy: normotension and hypertension, a fact repeatedly pointed out by Sir George Pickering $(75,76)$.

The fact that most physicians and scientists still use the terms hypertension and normotension, and also the term borderline hypertension, the topic of this seminar, does not mean that they do not recognize that blood pressure (BP) is a quantitative variable. The use of these terms reflects the realization that individuals with a certain level of BP have several common physiologic and epidemiologic characteristics which often mandate specific investigative and practical approaches. As will become evident during this seminar, the term borderline hypertension signifies not just a certain range of BP between "normotension" and "hypertension", but rather a clinical condition with recognizable and reproducible characteristics.

\section{DEFINITIONS}

The WHO has defined hypertension as systolic BP (SBP) $\geqslant 160$ and/or diastolic BP (DBP) $\geqslant 95 \mathrm{mmHg}$ and normotension as $\leqslant 140 / 90 \mathrm{mmHg}$, leaving the range between these two delineations to be called borderline hypertension (101). The Ann Arbor group has previously defined patients with borderline hypertension as those having, out of five indirect casual BPs within the last year, at least one with a diastolic value $\geqslant 90 \mathrm{mmHg}$ and at least one $\leqslant 90 \mathrm{mmHg}$ (45). Others have defined borderline hypertension as BP intermittently above $150 \mathrm{mmHg}$ systolic or $90 \mathrm{mmHg}$ diastolic (94). Since arterial pressure tends to increase with age in the Western world, all the above definitions have inherent problems, simply because they do not consider the age of the subject. However, the Ann Arbor group has recently taken age into consideration and defines borderline hypertension in the following manner: age 17-40: $>140 / 90,<160 / 100$; age $41-60:>150 / 90,<160 / 100$ and age $>60:>160 / 90,<175 / 100(40)$. Obviously the intent of all these classifications is to delineate the mildest possible form of hypertension. Consequently, the term borderline hypertension excludes the existence of BP-related target organ damage such as hypertensive retinopathy and left ventricular hypertrophy (with conventional methods) or impaired renal function.

A number of synonyms to borderline hypertension have been proposed. The term labile hypertension is not logical as it implies increased BP variability. Some of the early studies indicating a higher degree of BP variability in subjects with systolic blood pressure above $120 \mathrm{mmHg}$ as compared to those with BPs below this level, are open to serious criticism, e.g. that in the lower BP group the upward variability of the BP was limited by definition (it could reach a maximum of $120 \mathrm{mmHg}$ ) whereas no such restrictions existed in the high $\mathrm{BP}$ group (78).

Furthermore, several studies have demonstrated that there is no correlation between the level of BP and its variability when repeated measurements are made during 1-3 weeks $(10,26)$. In addition, BP fluctuates markedly

Requests for reprints to: L. Hansson, M.D., Dept. of Medicine, Östra Hospital, S-41685 Göteborg, Sweden. 
even in normotensive individuals (4). It is therefore not surprising to find that an excessive variability of BP has never been established as a characteristic feature of borderline hypertension. Even if the BP variability were increased, the importance of this finding would be questionable. The extreme ranges of BP do not seem to predict the risk of cardiovascular disease. Thus, Sokolow et al. (85) found that the five highest and five lowest BPs during a 24-hour recording did not relate to cardiovascular morbidity, whereas the average BP during that period carried an important predictive power. The term "labile" should be reserved for individuals with extremely variable BPs, irrespective of whether these occur in the normotensive, borderline or hypertensive range.

The term prehypertension indicates a condition which almost invariably leads to established hypertension. Since this is not the case, which will be shown later, the term is not logical. Latent hypertension points to a condition which may develop into hypertension or which may remain latent, and this term is accordingly a useful synonym. Marginal hypertension is also acceptable. whereas early essential hypertension should be avoided for the same reasons as prehypertension. However, borderline hypertension is such an accepted and commonly used expression that any attempt to use synonyms for this condition is likely to cause confusion. For this reason we would recommend that the use of synonyms be restricted.

\section{EPIDEMIOLOGY}

The prevalence of borderline hypertension has been studied in several population surveys. In the Bergen study, performed in the $1950 \mathrm{~s}, 8 \%$ of the males in the age group 20-30 years had borderline hypertension and $13 \%$ in the $30-40$ years group. The prevalence of borderline hypertension was somewhat lower in women below 50 years of age, but with increasing age this difference disappeared (6). Also in the US the prevalence of borderline hypertension increases rapidly with increasing age (7). The prevalence of borderline hypertension in university students in Michigan has been reported to be approximately $20 \%(40)$.

Accurate data about the prevalence of borderline hypertension in Sweden are lacking. However, if the prevalence data from the Alameda County BP study in California were valid also in Sweden, the total number of persons with borderline hypertension would exceed one million (of a total population of 8 millions) (Table I).

For a complete review of available data on the prevalence of borderline hypertension, see Julius and Schork (47). In this context it should be stressed again that the definition of borderline hypertension, and indeed also of hypertension, becomes crucial with advancing age. For example, a
Table I. Calculated number of persons with borderline hypertension in Sweden

Based on population data on Dec. 31, 1976. the total population of Sweden being 8236179 (90), and The Alameda County BP study (7)

\begin{tabular}{lrr}
\hline Age group & Males & Females \\
\hline $18-24$ & 19900 & 7600 \\
$25-44$ & 114200 & 54300 \\
$45-64$ & 163100 & 196700 \\
$>65$ & 106800 & 357400 \\
All & 403800 & 616000 \\
All males and females & \multicolumn{2}{c}{1019800} \\
\hline
\end{tabular}

population study of 70-year-old women in Göteborg indicated that no less than $48 \%$ had hypertension (92), demonstrating the dilemma of arbitrary definitions of hypertension. The incidence of borderline hypertension has repeatedly been found to be quite low, in the order of $1 \% /$ year of observation (47, 52).

\section{NATURAL HISTORY AND RISK FACTORS}

The later occurrence of established hypertension has repeatedly been found to be $2-5$ times more common in individuals with borderline hypertension than in those with initial normal BP. Still it should be stressed that only a minority of individuals with borderline hypertension later develop established hypertension. An approximate figure for the accumulated overall risk is commonly considered to be around $20 \%(44,70,73)$.

The morbidity and mortality from cardiovascular disease in the population with borderline hypertension is approximately twice as high as in a normotensive population (47). The increased morbidity in borderline hypertension shows a similar pattern to the morbidity observed in established hypertension. Thus, an excess in myocardial infarction. strokes, congestive heart failure and ECG changes has been reported $(32,51,57,62,88,96)$. Consequently it is likely, but not proven, that this higher morbidity occurs in the group ( $20 \%$ ) of patients who will later develop established hypertension (hypertension-specific cardiovascular morbidity).

A good example of morbidity in borderline hypertension can be found in the Framingham study, which showed a $50 \%$ increase in age-adjusted coronary heart disease $(50,51)$. Other studies have shown similar or higher (up to $200 \%$ ) increases in 
coronary morbidity in borderline hypertension (39, 47, 57). The Framingham study also found an almost doubled incidence of atherothrombotic brain infarction.

The mortality in borderline hypertension is also increased. One could question the specificity of this mortality since in the report by Levy et al. (57), patients with borderline hypertension had a greater tendency to commit suicide. However, the Framingham study shows that the excess mortality in borderline hypertension is specific.

A $50 \%$ increased overall mortality for men and a $75 \%$ increase for women with borderline hypertension as compared to normotensive control groups was reported. The increase is largely due to cardiovascular mortality, which was twice the normal rate for men and four times that for women in age group 67-74 (50). In younger age groups the increase in cardiovascular mortality was substantial but not as dramatic as in older ages (50).

As the risks for complications increase with rising $\mathrm{BP}(85)$, it is not surprising that a great deal of work and interest have gone into attempts to identify factors that predict future hypertension. As it happens, the best predictor for future hypertension is high BP, i.e. the initial level is the strongest predictor for $\mathrm{BP}$ in the future $(11,32,48,64,69,87)$. Another, independent predictive factor is tachycardia, which is not a benign sign $(70,87)$. Levy et al. found that when both transient hypertension and transient tachycardia were present, the incidence of later established hypertension was more than twice the incidence when only one of these factors was present (58).

Overweight is also associated with borderline and mild hypertension. High relative weight is a predictor of future hypertension, as is weight gain over a period of years $(32,37,38,70,87,89)$.

A positive family history of hypertension is more common in patients with borderline BP elevation (42), and established hypertension occurs more often in patients with a positive family history (29). The inheritance of arterial pressure is considered to be multigenetic but the exact mechanisms are not well known $(80,97)$.

Interest has recently been focused on possible interactions between environmental and geneticimmunological factors in the development of hypertension $(12,93)$. The question has been asked whether there are genetic indicators-e.g. certain HLA types-at least in some subpopulations in es- sential hypertension. If so, it might be possible to predict the prognosis or the risk for, e.g., vascular damage more reliably than is presently possible (27, 53). However, to our knowledge no such studies have been performed systematically in individuals with borderline hypertension.

In the overall US population the prevalence of borderline hypertension is very similar for black and white persons of both sexes, but established hypertension is twice as frequent in blacks, indicating that race may be considered as a risk factor and that blacks carry a greater risk for progression from borderline to sustained hypertension (40).

Using multiple logistic function to discern the quintile of the population with the highest risk of developing hypertension within 5 years, Stamler et al. (87) could identify at most $55 \%$ of all expected hypertensives in that quintile.

A number of tests have been designed and employed in attempts to identify persons with an augmented risk of developing future hypertension, e.g. cold pressor test, salt loading, reaction to mental arithmetic, digital vascular reactivity to noradrenalin, apparent noradrenalin secretion test and tritiated noradrenalin test as well as different combinations of these. By and large such tests have proved to be of no predictive value, or alternatively they cannot be employed in practice or the needed Jong-term follow-up is still lacking (40, 91). This holds true also for a new and most interesting approach: the abnormal $\mathrm{Na}+$ and $\mathrm{K}+$ net fluxes in erythrocytes of essential hypertensive patients (also in relatives to hypertensive patients and in some women with hypertension during pregnancy) (25). Whether these abnormalities can really be used as markers for hypertension remains to be confirmed.

\section{HUMORAL FACTORS}

Catecholamine concentrations in urine or plasma are frequently used as indicators of sympathetic activity. It is, however, doubtful that patients with established hypertension have increased sympathetic activity as reflected by increased release of catecholamines $(8,15,18,19,23,34,55,59,68,74$, 81 ). Age is of importance in this setting, since plasma concentration of noradrenalin is positively correlated with age $(23,34,74,81)$. Activation of the cardiac sympathetic neurones increases urinary catecholamine excretion (9), whereas moderate activation of the peripheral sympathetic nervous 
Table II. Hemodynamics in borderline hypertension

\begin{tabular}{|c|c|c|c|c|}
\hline & $\begin{array}{l}\text { Controls } \\
(n=29)\end{array}$ & $\begin{array}{l}\text { Whole patient } \\
\text { group } \\
(n=44)\end{array}$ & $\begin{array}{l}\text { Hyperkinetic } \\
\text { subgroup } \\
(n=20)\end{array}$ & $\begin{array}{l}\text { Normokinetic } \\
\text { ubgroup } \\
(n=24)\end{array}$ \\
\hline \multicolumn{5}{|l|}{ Blood pressure (mmHg) } \\
\hline SBP & 120 & $137^{* * *}$ & $138^{* * *}$ & $136^{* * *}$ \\
\hline DBP & 71 & $75^{* *}$ & $76^{* *}$ & $74^{*}$ \\
\hline Mean & 88 & $95^{* * *}$ & $97^{* * *}$ & $94^{* * *}$ \\
\hline Heart rate (beats/min) & 65 & 69 & $76^{* * *}$ & 65 \\
\hline Stroke volume (ml) & 98 & $111^{* *}$ & $119^{* * *}$ & $\triangle \quad 104$ \\
\hline Cardiac output (1/min) & 6.1 & $7.3^{* * *}$ & $8.6^{* * *}$ & $\triangle \triangle \triangle \quad 6.2$ \\
\hline Cardiac index $\left(1 / \mathrm{min} \cdot \mathrm{m}^{2}\right)$ & 3.33 & $3.81^{*}$ & $4.55^{* * *}$ & $\triangle \triangle \triangle \quad 3.19$ \\
\hline Total peripheral resistance $(\mathrm{mmHg} / 1 / \mathrm{min})$ & 14.8 & $13.4^{*}$ & $11.2^{* * *}$ & $\triangle \triangle \triangle 15.2$ \\
\hline $\begin{array}{l}\text { Minimal vascular resistance in the hands } \\
(\mathrm{mmHg} /(\mathrm{ml} / \mathrm{min} \cdot 100 \mathrm{ml}))\end{array}$ & 1.69 & $1.87^{*}$ & 1.71 & $\triangle \quad 1.99^{* *}$ \\
\hline Body weight $(\mathrm{kg})$ & 65.9 & $73.8^{* * *}$ & $71.4^{*}$ & $75.8^{* * *}$ \\
\hline
\end{tabular}

${ }^{*} p<0.05,{ }^{* *} p<0.01,{ }^{* * *} p<0.001$ in comparison with controls. $\triangle p<0.05, \triangle \triangle p<0.01, \triangle \triangle \triangle p<0.001$ in comparison with hyperkinetic subgroup (Sivertsson et al.: Unpublished data).

system does not increase plasma concentrations of adrenalin or noradrenalin $(1,61)$. Some patients with established hypertension appear to have a true neurogenic hypertension and their BP can be normalized following total autonomic blockade (16). Hypertensive patients showing higher noradrenalin levels are usually young $(23,34,81)$ and have also been reported to have increased plasma renin activity (16).

In comparison with normotensive individuals, borderline hypertensives usually have normal resting plasma and urinary catecholamine concentrations $(8,67)$. Physical exercise induces elevation of both noradrenalin and adrenalin plasma concentration but patients with borderline hypertension do not behave differently from normal controls in this respect. Patients with borderline hypertension have increased excretion of urinary catecholamines during mental stress $(19,67)$ and also an increased catecholamine response to upright posture $(19,54)$. Poststress plasma catecholamines have recently been shown to be increased also in individuals with a genetic risk of developing hypertension as well as in borderline hypertensives (20).

As a group, borderline hypertensives have higher plasma renin activity than normotensive individuals and patients with established hypertension (24). Patients with borderline hypertension have been subdivided by their renin status (17) and approximately $35 \%$ are in the "high renin" group, $45 \%$ in the "normal renin" group and $20 \%$ in the "low renin" group (17). Patients with "hyperkinetic circulation" usually have high plasma renin activity (65).
Total autonomic blockade with propranolol, atropine, and phentolamine normalizes the BP both in patients with high renin borderline hypertension and in high renin established.hypertension $(16,17)$. However, in patients with normal or low renin hypertension the BP remains elevated alşo following total autonomic blockade $(1,7)$. This would seem to indicate that the high renin hypertensives have a neurogenic type of BP: elevation. Obviously, the plasma renin activity per se does not induce the $\mathrm{BP}$ elevation in these patients, since $\beta$-adrenoceptor blockade with propranolol, which causes a marked decrease in plasma renin levels, does not reduce the elevated BP (43).

\section{PERSONALITY TRAITS}

A few reports indicate that patients with borderline hypertension differ from normal controls in a number of psychological ways $(28,30)$. Thus, they are more submissive and have more suppressed hostility (28). They also more often exhibit disturbances in sexual roles and have difficulties in interactions with other people (49). These aspects indicate that borderline hypertension could be regarded as a psychosomatic disease.

\section{HEMODYNAMICS}

\section{Cardiac output}

It is well documented that cardiac output at rest is increased in patients with borderline hypertension as a group, in comparison with normotensive indi- 
viduals (47). However, this does not mean that all individuals with borderline hypertension have an increased cardiac output. But in $30-50 \%$ the cardiac output exceeds the value found in control subjects by 2 S.D. or more. This difference between borderline hypertensives and normotensives seems to decrease with increasing age $(41,60)$. Some studies indicate that the high output is caused by an elevated heart rate $(24,41,60,63,79)$, others that it is due to an increased stroke volume $(3,21)$ while still others have demonstrated that both factors are involved $(13,78,100)$ (Table II).

The elevation of cardiac output is maintained by an increased sympathetic and a reduced vagal activity to the heart. which points to an altered central nervous activity in these individuals. Thus, cardiac output normalized after autonomic blockade with propranolol and atropine (45). Since the sensitivity of the $\beta$-adrenoceptors in the myocardium is decreased rather than increased in borderline hypertension, the high output state was not caused by local cardiac effects (43).

\section{Blood rolume}

Most studies show that blood volume or plasma volume is normal or slightly reduced in borderline hypertension $(2,21,24,63)$ while a few studies show significantly reduced values $(22,46,78)$. Cardiopulmonary blood volume is probably normal in patients with borderline hypertension (78). In relation to total blood volume, cardiopulmonary blood volume has been found to be normal (79) or increased (78). In patients with hyperkinetic borderline hypertension, the cardiopulmonary blood volume appears to be increased both in absolute and in relative terms (14). This centralization of blood from the periphery is probably a consequence of an increased vasomotor nerve tone on the capacitance vessels (78). Such a redistribution of the blood pool might influence stroke volume and cardiac output by increasing the venous return. Although there is a positive correlation between cardiac output and cardiopulmonary blood volume (14), this does not prove a causal connection since vasomotor nerve activity may influence both these variables. On the contrary, some data indicate that the two factors are not causally related. Thus, autonomic nerve blockade normalizes cardiac output but not the central blood volume (14). A changed relation between central blood volume and stroke volume or cardiac index (increased stroke volume in relation to central blood volume) supports the idea that vasomotor nerve activity is the main determinant of the increased cardiac output in patients with borderline hypertension (14).

\section{Peripheral vessels and vascular resistance}

At rest, total peripheral resistance in borderline hypertension is within normal limits, or in fact slightly reduced (Table II). It has been pointed out, though, that in relation to cardiac output, vascular resistance is increased (46). The vascular resistance can be brought into the normal range by means of phentolamine in about $30 \%$ of patients with borderline hypertension (43). During intense physical exercise, total vascular resistance in borderline hypertension remains elevated $(60,79)$. Moreover, during infusion of dextran, the vascular resistance in borderline hypertension fails to adjust to the increased cardiac output (45).

Adaptive structural changes in the resistance vessels seem to occur already in mild forms of hypertension $(83,84)$ (Table II). This is in agreement with the echocardiographic observation of left ventricular hypertrophy in borderline hypertensive patients (56). A recent study has shown decreased venous distensibility in borderline hypertension (94). The claim was made that this decreased distensibility was to a certain extent due to structural changes in the veins (94). However, the scientific support for this claim is not convincing and the findings may be explained by increased smooth muscle tone.

\section{MANAGEMENT}

It has been pointed out above that borderline hypertension constitutes an important risk factor for future cardiovascular complications. A logical consequence of this would be to lower the BP. However, available data so far, notably the Veterans Administration studies, have shown positive therapeutic effects as regards morbidity and mortality only in patients whose DBPs were $105 \mathrm{mmHg}$ or higher $(98,99)$. However, the HDFP (Hypertension Detection and Follow-up Program) study $(35,36)$ demonstrates for the first time a clear reduction in mortality also in patients whose DBPs were 90-105 $\mathrm{mmHg}$. Obviously, these important new results will have a profound effect on management policies for patients with mild hypertension.

Before any kind of intervention is considered in 
patients with borderline hypertension, it is obvious that the BP level should be determined with the greatest possible accuracy. Therefore, repeated measurements of $\mathrm{BP}$ with a reliable and standardized technique become mandatory.

Borderline hypertensive patients are frequently overweight and since weight reduction lowers BP in obese hypertensive patients (33), it becomes obvious that reduction of body weight should be attempted in borderline patients, too. The BP-lowering effects of weight reduction have been shown to be independent of salt restriction (77). Still, salt reduction of a moderate degree will also lower BP. A reduction of daily salt intake from about 10 to $5 \mathrm{~g}$ may reduce the BP approximately $10 / 5 \mathrm{mmHg}(66$, 71). Dietary advice may also be beneficial in other ways, e.g. by correcting hyperlipidemia and glucose metabolism disturbances.

In a review of non-pharmacological treatment of hypertension, Blackburn (5) pointed out that "Exercise can be recommended to mildly hypertensive patients, as to the entire public, for its long-term benefit in weight control in a sedentary society. However, it is not established that cardiovascular mechanisms involving autonomic nervous activity which are affected by high level conditioning exercise, have in fact, any independent or long-term antihypertensive effect."

Behavioural methods to reduce high BP include biofeedback, relaxation, psychotherapy, environmental modification and placebo. In an extensive review of this field, Shapiro et al. (82) concluded that "widespread and uncritical application of behavioural methods to the treatment of high blood pressure is premature".

In the management of patients with hypertension, it is obvious that advice and information play important roles. However, such information should be given with care. Canadian steel workers tended to have longer periods of non-attendance when aware of a hypertensive condition than controls who were not aware of having similar BP levels (31).

In conclusion, non-pharmacological treatment and regular check-ups of BP constitute the basis for managing borderline hypertensive patients. Drug therapy is not recommended in cases of truly borderline hypertension, i.e. with DBPs sometimes below, sometimes slightly above $90 \mathrm{mmHg}$. However, the recent findings of the HDFP group clearly support the opinion that pharmacological treatment should be instituted in hypertensive patients, even in the "mild range", i.e. with DBPs between 90 and $105 \mathrm{mmHg}(35,36)$. Furthermore, treatment, particularly with a $\beta$-adrenoceptor blocking agent, can be considered in borderline hypertensive patients with subjective symptoms related to their condition, e.g. disturbing palpitations or tachycardia.

It also stands to reason that treatment shall be attempted in those patients with borderline hypertension who are at high risk to develop future hypertension due to their family history, race, or uncorrectable other risk factors. Only moderate doses of drugs and only monotherapy are recommended in such cases. It would be unwise to apply the same aggressive stepped-care approach to treatment that is usually used in established hypertension.

\section{CONCLUSIONS}

Borderline hypertension refers to that gray zone between clearly normotensive and hypertensive BP values. It is interesting to note that a number of pathophysiological characteristics make it possible to separate borderline hypertension, on the one hand, from normotension and, on the other, from established hypertension. All the available data indicate that borderline hypertension constitutes the first phase in the development of established hypertension, although it should be pointed out that individuals with BPs within the borderline range by no means are bound to develop established hypertension. It is also worth noting that BPs within the borderline hypertensive range are associated with increased risks for cardiovascular morbidity and mortality. The newly published and clearly positive results of the HDFP study regarding antihypertensive therapy in mild hypertension will probably contribute to increased attention of this interesting clinical entity.

\section{REFERENCES}

1. Andrén, L., Hansson, L., Björkman, M., Jonsson, A. \& Borg, K. O.: Hemodynamic and hormonal changes induced by noise. Acta Med Scand (Suppl) 625: $13,1979$.

2. Bello, C. T., Sevy, R. W. \& Harakal, C.: Varying hemodynamic patterns in essential hypertension. Am J Med Sci 250: 24, 1965.

3. - Relationship between clinical severity of disease and hemodynamic patterns in essential hypertension. Am J Med Sci 253: 194, 1967.

4. Bevan, A. T., Honour, A. J. \& Stott, F. H.: Direct 
arterial pressure recordings in unrestricted man. Clin Sci 36: 329, 1969.

5. Blackburn. H.: Non-pharmacologic treatment of hypertension: Discussion. Ann N Y Acad Sci 304: 236, 1978.

6. Bøe, J., Humerfelt, S. \& Wedervang. F.: The blood pressure in a population: Blood pressure readings and height and weight determinations in the adult population of the city of Bergen. Acta Med Scand (Suppl) 321: 1. 1957.

7. Borhani. N. O. \& Smith-Borkman. T.: Alameda County blood pressure study. California Dept. Public Health, Berkeley 1968.

8. De Quattro. V. \& Chan, S.: Raised plasmacatecholamines in some patients with primary hypertension. Lancet 1: 806, 1972.

9. De Quattro, V. \& Sjoerdsma. A.: Catecholamine turnover in normotensive and hypertensive man: Effects of antiadrenergic drugs. J Clin Invest 47:2359. 1968.

10. Diehl. H. S.: The variability of blood pressure. Morning and evening studies. Arch Intern Med 43: 835, 1929.

11. Dunn. J. P., Ipsen, J., Elsom, K. O. \& Othani, M.: Risk factors in coronary artery disease, hypertension and diabetes. Am J Med Sci 259: 309, 1970.

12. Editorial: Immunogenetics and essential hypertension. Lancet 2: 409, 1978.

13. Eich, R. H.. Peters, R. J. \& Cuddy, R. P.: The hemodynamics in labile hypertension. Am Heart $J$ 63: 188.1962.

14. Ellis, C. N. \& Julius, S.: Role of central blood volume in hyperkinetic borderline hypertension. $\mathrm{Br}$ Heart J 35: 450, 1973.

15. Engelman, K., Portnoy, B. \& Sjoerdsma. A.: Plasma catecholamine concentrations in patients with hypertension. Circ Res (Suppl) 1: 141, 1970.

16. Esler, M., Julius, S., Zweifler, A. J., Randall, O., Harburg, E., Gardiner, H. \& De Quattro, V.: Mild high-renin essential hypertension. Neurogenic human hypertension. N Engl J Med 296: 405, 1977.

17. Esler, M. D., Julius, S., Randall. O. T., Ellis, C. N. \& Kashima, T.: Relation of renin status to neurogenic vascular resistance in borderline hypertension. Am J Cardiol 36: 708, 1975.

18. Esler. M. D. \& Nestel. P. J.: High catecholamine essential hypertension. Clinical and physiological characteristics. Aust NZ J Med 3: 117, 1973.

19. - Renin and sympathetic nervous system responsiveness to adrenergic stimuli in essential hypertension. Am J Cardiol 32: 643. 1973.

20. Falkner, B., Onesti, G., Angelakos, E. T., Fernandes, $M$. \& Langman, C.: Cardiovascular response to mental stress in normal adolescents with hypertensive parents. Hemodynamics and mental stress in adolescents. Hypertension 1:23, 1979.

21. Finkjelman, S., Worcel, M. \& Agrest. A.: Hemodynamic patterns in essential hypertension. Circulation 31: 356, 1965.

22. Fouad, F. M., Tarazi, R. C. \& Dustan, H. P.: Hemodynamics of essential hypertension in young subjects. Am Heart J 96: 646, 1978.
23. Franco-Morcelli, R., Elghozi, J. L., Joly, E., Di Giuilio, S. \& Meyer, P.: Increased plasma adrenalin concentrations in benign essential hypertension. $\mathrm{Br}$ Med J 2: 1251, 1977.

24. Frohlich, E. D., Kozul, V. J., Tarazi, R. C. \& Dustan. H. P.: Physiological comparison of labile and essential hypertension. Circ Res (Suppl) 1: 55, 1970.

25. Garay, R. P., De Mendonca, M., Elghozi, J. L., Devynck, M. A., Dagher, G., Pernollet, M. G., Oddos, J., Grichois, M. L. Ben-Ishay, D. \& Meyer, P.: Proceedings of the sixth scientific meeting of the International Society of Hypertension, Göteborg 1979.

26. Glock, C. Y., Vought, R. L., Clark, E. G. \& Schweitzer. M. D.: Studies in hypertension. Variability of daily blood pressure measurements in the same individuals over a three week period. J Chron Dis $4: 469,1956$.

27. Gudbrandsson. T., Herlitz, H., Hansson, L. \& Rydberg. L.: HLA-antigens in essential malignant hypertension. Clin Sci. Accepted for publication 1980.

28. Harburg. E., Julius, S., McGinn, N. F., McLeod, J. \& Hoobler, S. W.: Personality traits and behavioural patterns associated with systolic blood pressure levels in college males. J Chron Dis 17:405, 1964.

29. Harlan, W. R., Osborn, R. K. \& Graybiel, A.: A longitudinal study of blood pressure. Circulation 26: $530,1962$.

30. Harris, R. E., Sokolow, M., Carpenter, L. G., Freedman. M. \& Hunt, S. P.: Response to psychologic stress in persons who are potentially hypertensive. Circulation 7:874, 1953.

31. Haynes, R. B., Sackett, D. L., Taylor, D. W., Gibson. E. S. \& Johnson. A. L.: Increased absenteeism from work after detection and labeling of hypertensive patients. N Engl J Med 299: 741, 1978.

32. Heyden, S., Bartel, A. G., Hames, C. G. \& McDonough, J. R.: Elevated blood pressure levels in adolescents, Evans County, Georgia. JAMA 209: 1683. 1969.

33. Heyden, S., Tyroler, H. A.. Hames, C. G. \& Bartel, J. W.: Diet treatment of obese hypertensives. Clin Sci Mol Med 45: 209, 1973.

34. Hofman. A., Boomsma. F., Schalekamp. M. A. D. H. \& Walkenburg, H. A.: Raised blood pressure and plasma noradrenalin concentrations in teenagers and young adults selected from an open population. $\mathrm{Br}$ Med J 1: 1536. 1979.

35. Hypertension Detection and Follow-up Program Cooperative Group: Five-year findings of the hypertension detection and follow-up program. I. Reduction in mortality of persons with high blood pressure, including mild hypertension. JAMA 242: 2562. 1979.

36. - Five-year findings of the hypertension detection and follow-up program. II. Mortality by race, sex and age. JAMA 242: 2572. 1979.

37. Johnson, A. L.. Cornoni, J. C., Cassel, J. C., Tyroler, H. A., Heyden, S. \& Hames, C.: Influence of race, sex and weight on blood pressure behaviour in young adults. Am J Cardiol 35: 523, 1975.

38. Johnson, B. C.. Karunas, T. M. \& Epstein, F. H.: Longitudinal change in blood pressure in individuals, 
families and social groups. Clin Sci Mol Med 45:35s, 1973.

39. Julius, S.: Borderline hypertension: epidemiologic and clinical implications. In: Hypertension (ed. J. Genest, E. Koiw \& O. Kuchel), p. 630. McGrawHill, New York 1977.

40. - Borderline hypertension: Clinical and pathophysiological significance. Ergeb Inn Med Kinderheilkd 41: 51, 1978.

41. Julius, S. \& Conway, J.: Hemodynamic studies in patients with borderline blood pressure elevation. Circulation 38: 282, 1968.

42. Julius, S., Ellis, C. N., Pascual, A. V., Matice, M., Hansson, L., Hunyor, S. N. \& Sandler, L. N.: Home blood pressure determination: Value in borderline ("labile") hypertension. JAMA 229: 663, 1974.

43. Julius, S. \& Esler, M.: Autonomic nervous cardiovascular regulation in borderline hypertension. Am J Cardiol 36: 685, 1975.

44. Julius, S., Harburg, E. \& McGinn, N. F.: Relationship between casual blood pressure readings in youth and at age 40: A retrospective study. J Chron Dis 17: 397, 1964

45. Julius, S., Pascual, A. V. \& London, R.: Role of parasympathetic inhibition in the hyperkinetic form of borderline hypertension. Circulation 44:413, 1971.

46. Julius, S. \& Sannerstedt, R.: Hemodynamic abnormalities in borderline blood pressure elevation. Circulation (Suppl) 3: 116, 1969

47. Julius, S. \& Schork, M. A.: Borderline hypertension-A critical review. J Chron Dis 23: 723, 1971

48. - Predictors of hypertension. Ann NY Acad Sci 304: 333, 1978.

49. Kalis, B. L., Harris, R. E., Bennett, L. F. \& Sokolow, M.: Personality and life history factors in persons who are potentially hypertensive. J Nerv Ment Dis 132: 457, 1961.

50. Kannel, W. B.: Importance of hypertension as a major risk factor in cardiovascular disease. In: Hypertension (ed. J. Genest, E. Koiw \& O. Kuchel), p. 888. McGraw-Hill, New York 1977.

51. Kannel, W. B., Schwartz, M. J. McNamara, P. $\mathrm{M}$.: Blood pressure and risk of coronary heart disease: The Framingham study. Dis Chest 56: 43, 1969.

52. Kooperstein, S. I., Schifrin, A. \& Leahy, T. J.: Level of initial blood pressure and subsequent development of essential hypertension: $A$ ten and fifteen year follow-up study. Am J Cardiol 10:416, 1962.

53. Kristensen, B. Ø., Andersen, P. H., Lamm, L. U. \& Kissmeyer-Nielsen, F.: HLA-antigens in essential hypertension. Tissue Antigens 10: 70, 1977.

54. Kuchel, O., Cuche, J. L., Hamet, P., Boucher, R., Barbeau, A. \& Genest, J.: The relationship between adrenergic nervous system and renin in labile hyperkinetic hypertension. In: Hypertension ' 72 (ed. J Genest \& E. Koiw), p. 118. Springer-Verlag, New York 1972

55. Lake, C. R., Ziegler, M. G., Coleman, M. D. \& Kopin, I. J.: Age-adjusted plasma norepinephrine levels are similar in normotensive and hypertensive subjects. N Engl J Med 296: 208, 1977.

56. Lehner, J. P., Safar, M. E. \& Dimitriu, U. M.: Systolic time intervals and echocardiographic findings in borderline hypertension. Eur J Cardiol 9: 319, 1979.

57. Levy, R. L., Hillman, C. C. \& Stroud, W. D.: Transient hypertension: lts significance in terms of later development of sustained hypertension and cardiovascular-renal disease. JAMA 126: 829, 1944.

58. Levy, R. L., White, P., Stroud, W. D. \& Hillman, C. C.: Transient tachycardia. JAMA 129: 585, 1945.

59. Louis, W. J., Doyle, A. E. \& Anavekar, S.: Plasma norepinephrine levels in essential hypertension. $\mathrm{N}$ Engl J Med 288: 599, 1973.

60. Lund-Johansen, P.: Hemodynamics in early essential hypertension. Acta Med Scand (Suppl) 482. 1967.

61. Mancia, G., Leonetti, G., Picotti, G. B., Ravazzoni, C., Ferrari, A., Gregorini, L., Pomidossi, G., Sala, C. \& Zanchetti, A.: Plasma catecholamine and blood pressure responses to sympathetic activation induced by the carotid baroreflex in man. Proceedings of the Sixth Scientific Meeting of the International Society of Hypertension, Göteborg 1979.

62. Mathewson, F. A.: Blood pressure in Canadian aviators: A fifteenth year report. Trans Assoc Life Ins Med Dir 50: 218, 1966.

63. Messerli, F. H., DeCarvaho, J. G. R., Christie, B. \& Frohlich, E. D.: Essential hypertension in black and white subjects. Hemodynamic findings and fluid volume state. Am J Med 67: 27, 1979.

64. Miall, W. E. \& Chinn, S.: Screening for blood pressure: Some epidemiological observations. Br Med J 3: $595,1974$.

65. Molzahn, M., Dissmann, T. H., Halim, S., Lohmann, S. W. \& Oelkers, W.: Orthostatic changes of hemodynamics, renal function, plasma catecholamines and plasma renin concentration in normal and hypertensive man. Clin Sci 42: 209, 1972.

66. Morgan, T., Gillies, A., Morgan, G., Adam, W., Wilson, M. \& Carney, S.: Hypertension treated by salt restriction. Lancet 1:228, 1978.

67. Nestel, P. J.: Blood pressure and catecholamine excretion after mental stress in labile hypertension. Lancet 1: 692, 1969.

68. Nestel, P. J. \& Doyle, A. E.: The excretion of free noradrenalin and adrenalin by healthy young subjects and by patients with essential hypertension. Aust Ann Med 17:295, 1968.

69. Oberman, A., Lane, N. E., Harlan, W. R., Graybiel, A. \& Mitchell, R. E.: Trends in systolic blood pressure in the thousand aviator cohort over a twenty year period. Circulation 36: 812, 1967.

70. Paffenbarger, R. S., Jr, Thorne, M. C. \& Wing, A. L.: Chronic disease in former college students. 8. Characteristics in youth predisposing to hypertension in later years. Am J Epidemiol 88: 25, 1968.

71. Parijs, J., Joossens, J. V., Van der Linden, L., Verstreken, G. \& Amery, A. K. P. C.: Moderate sodium restriction and diuretics in the treatment of hypertension. Am Heart J 85: 22, 1973. 
72. Paul, O.: Risks of mild hypertension: A ten year report. Br Heart J (Suppl) 1: 116, 1971.

73. - Complications of mild hypertension. Ann NY Acad Sci 304: 59, 1978.

74. Pedersen, E. B. \& Christensen, N. J.: Catecholamines in plasma and urine in patients with essential hypertension determined by double-isotope derivative techniques. Acta Med Scand 198:373, 1975.

75. Pickering, G. W.: High blood pressure, 2 nd ed. Churchill, London 1968.

76. - Normotension and hypertension: The mysterious viability of the false. Am J Med 65:561, 1978.

77. Reisin. E., Rachel, A., Modan, M., Silverberg, D. S., Eliahou, H. E. \& Modan, B.: Effect of weight loss without salt restriction on the reduction of blood pressure in overweight hypertensive patients. N Engl J Med 298: 1, 1978.

78. Safar, M. E., London, G. M. \& Weiss, Y. A.: Vascular reactivity to norepinephrine and hemodynamic parameters in borderline hypertension. Am Heart $\mathbf{J}$ 89: $480,1975$.

79. Sannerstedt, R.: Hemodynamic response to exercise in patients with arterial hypertension. Acta Med Scand (Suppl) 458, 1966.

80. Schull, W. J., Harburg, E., Schork, M. A. \& Chakraborty, R.: Heredity, stress and blood pressure, a family set method. J Chron Dis 30: 701, 1977.

81. Sever, P. S., Birch, M., Osikowska, B. \& Tunbridge, R. D. G.: Plasma-noradrenaline in essential hypertension. Lancet 1: 1078, 1977.

82. Shapiro. A. P., Schwartz, G. E., Ferguson, D. C. E., Redmond, D. P. \& Weiss, S. M.: Behavioural methods in the treatment of hypertension. Ann Intern Med 86: 626, 1977.

83. Sivertsson, R. \& Sannerstedt, R.: Mild elevation of arterial blood pressure and structural vascular changes. In: Mild hypertension: natural history and management. Proceedings of the joint WHO/ISH meeting in Susono. Japan (ed. F. Gross \& T. Strasser) 1979

84. Sivertsson, R., Sannerstedt, R. \& Lundgren, Y.: Evidence for peripheral vascular involvement in mild elevation of blood pressure in man. Clin Sci Mol Med 51:65, 1976.

85. Sokolow, M., Werdegar, D., Kain, K. \& Hinman, A. T.: Relationship between level of blood pressure measured casually and by portable recorders and severity of complications in essential hypertension. Circulation 34: 279, 1966.

86. Stamler, J.: The mass treatment of hypertensive disease: Defining the problem. Ann NY Acad Sci 304: 333, 1978.

87. Stamler, J., Berkson, D. M. \& Dyer, A.: Relationship of multiple variables to blood pressure. In:
Epidemiology and control of hypertension (ed. O. Paul), p. 307. Symposia Specialists, Miami 1975.

88. Stamler, J., Lindberg, H. A. \& Berkson, D. M.: Epidemiological analysis of hypertension and hypertensive disease in the labor force of a Chicago utility company. Proc Counc High Blood Press Res 7:23, 1958.

89. Stamler, R., Stamler, J., Riedlinger, W. F., Algera, G. \& Roberts, R. H.: Weight and blood pressure. Findings in hypertensive screening of 1 million Americans. JAMA 240: 1607, 1978.

90. Statistiska Centralbyrån: Population by age, marital status and sex. Statistisk Årsbok 1977. p. 39. Liber Förlag, Stockholm 1977.

91. Suck, A. F., Mendlowitz, M., Wolf, R. L., Gitlow, S. E. \& Naftchi, N. E.: Identification of essential hypertension in patients with labile blood pressure. Chest 59:402, 1971.

92. Svanborg, A.: Seventy-year-old people in Gothenburg. A population study in an industrialized Swedish city. Il. General presentation of social and medical conditions. Acta Med Scand (Suppl) 611:5, 1977.

93. Svendsen, U. G.: The importance of the thymus for hypertension and hypertensive vascular disease in rats and mice. Acta Pathol Microbiol Scand (Suppl) 276. 1978.

94. Takeshita, A. \& Mark, A. L.: Decreased venous distensibility in borderline hypertension. Hypertension 1: 202, 1979.

95. Thomas, C. B.: Developmental patterns in hypertensive cardiovascular disease: Fact or fiction? Bull NY Acad Med 45: 831, 1969.

96. Thomson, K. J.: Some observations on the development and course of hypertensive vascular disease. Proc Ann Meet Med Sect Amer Life Conv 38: 85, 1950 .

97. Tyroler, H. A.: The Detroit project studies of blood pressure. J Chron Dis 30:613, 1977.

98. Veterans Administration Cooperative Study Group on Antihypertensive Agents: Effects of treatment on morbidity in hypertension. Results in patients with diastolic blood pressure averaging 115 through 129 mmHg. JAMA 202: 1028, 1967.

99. - Effects of treatment on morbidity in hypertension. Results in patients with diastolic blood pressure averaging 90 through $114 \mathrm{mmHg}$. JAMA 213:1143, 1970.

100. Widimsky, J., Fejfarova, H. M. \& Fejfar, Z.: Der jugendliche Hochdruck. Arch Kreislaufforsch 28: $100,1958$.

101. World Health Organization: Report of a WHO Expert Committee. Arterial hypertension. WHO Techn Rep Ser 628, 1978. 